\title{
Heterocontrole do flúor nas águas de abastecimento público: resultados e experiência de 13 anos de vigilância
}

\author{
External control of fluoride in public water supply: results and experience of \\ 13 years of surveillance \\ Control externo de flúor en las aguas de abastecimiento público: resultados y \\ experiencia de 13 años de vigilancia \\ Suzely Adas Saliba MOIMAZ \\ Luis Felipe Pupim dos SANTOS \\ Tânia Adas SALIBA \\ Nemre Adas SALIBA \\ Orlando SALIBA \\ Programa de Pós-Graduação em Odontologia Preventiva e Social, Faculdade de Odontologia de Araçatuba \\ Univ Estadual Paulista, UNESP 16015.050 Araçatuba-SP, Brasil
}

\begin{abstract}
Resumo
A adição de flúor nas águas de abastecimento público é uma medida de saúde pública utilizada para prevenção de cárie dentária. Este estudo objetivou analisar os resultados dos níveis de fluoreto das águas de abastecimento público de 40 cidades do estado de São Paulo, no período de novembro de 2004 a dezembro de 2017, e relatar as experiências de um projeto da Faculdade de Odontologia de Araçatuba (Unesp) que promove o heterocontrole do flúor. As amostras foram coletadas em pontos preestabelecidos de acordo com a quantidade e localização das fontes de captação de água das cidades. A leitura das amostras foi realizada utilizando-se um analisador de íons acoplado a um eletrodo específico. De 34993 amostras, 52,47\% continham teores de flúor dentro do intervalo recomendado. Comparando-se o primeiro ano completo do estudo com o último, em 2005, 51,75\% dos pontos de coleta possuiam teores médios de flúor entre 0,55 e $0,84 \mathrm{mgF} / \mathrm{L}$, e em $2017,60,94 \%$ estavam dentro desse intervalo. O menor valor encontrado foi $0,04 \mathrm{mgF} / \mathrm{L}$, e a amostra era proveniente de uma fonte alternativa do município de Birigui; já o máximo valor verificado foi $2,28 \mathrm{mgF} / \mathrm{L}$, sendo a amostra proveniente de Valparaíso. No decorrer do projeto, houve grande melhora na adequação do método nas localidades. A maior parte dos municípios possui flúor nos teores preconizados em suas águas. A vigilância e o heterocontrole são importantes estratégias que auxiliam o método a alcançar seu efeito preventivo, garantindo o direito da população a receber água de qualidade para seu consumo.

Descritores: Fluoretação; Saúde Pública; Saúde Bucal; Abastecimento de Água.
\end{abstract}

\section{Abstract}

The addition of fluoride in public water supply is a public health measure used to prevent tooth decay. The objective of this study was to analyze the fluoride levels of public water supply in 40 cities in the state of São Paulo from November 2004 to December 2017 and report on the experiences of the project of the São Paulo State University (Unesp), School of Dentistry, Araçatuba, which promotes fluoride heterocontrol. Samples were collected at preestablished points according to the quantity and location of water abstraction sources in the cities. The samples were read using an ion analyzer coupled to a specific electrode. Of 34993 samples, $52.47 \%$ contained fluorine levels within the recommended range. Comparing the first year of the study with the latter, in 2005 , $51.75 \%$ of the collection points had mean fluorine levels between 0.55 and $0.84 \mathrm{mgF} / \mathrm{L}$, and in $2017,60.94 \%$ were in this interval. The lowest value was $0.04 \mathrm{mgF} / \mathrm{L}$, and the sample was from an alternative source in the municipality of Birigui; already the maximum verified value was $2.28 \mathrm{mgF} / \mathrm{L}$, being the sample coming from Valparaiso. During the project, there was a great improvement in the adequacy of the method in the localities. Most of the municipalities have fluoride in the recommended levels in their public water supply. Surveillance and heterocontrol are important strategies that help the method achieve its preventive effect, guaranteeing the right of the population to receive quality water for their consumption.

Descriptors: Fluoridation; Public Health; Oral Health; Water Supply.

\section{Resumen}

La adición de flúor en las aguas de abastecimiento público es una medida de salud pública utilizada para la prevención de caries. Este estudio objetivó analizar los resultados de los niveles de fluoruro de las aguas de abastecimiento público de 40 ciudades del estado de São Paulo, de noviembre de 2004 a diciembre de 2017, y relatar las experiencias del proyecto de la Facultad de Odontología de Araçatuba (Unesp) que promueve el heterocontrole del flúor. Las muestras fueron recolectadas en puntos preestablecidos de acuerdo con la cantidad y localización de las fuentes de captación de agua. La lectura de las muestras se realizó utilizando un analizador de iones acoplado a un electrodo específico. De 34993 muestras, el 52.47\% contenía contenidos de flúor dentro del intervalo recomendado. En comparación con el primer año completo del estudio con el último, en 2005, el 51,75\% de los puntos de recolección poseían niveles medios de flúor entre 0,55 y 0,84 mgF L, y en 2017, el 60,94\% estaban dentro de ese intervalo. El menor valor encontrado fue $0,04 \mathrm{mgF} / \mathrm{L}$, y la muestra provenía de una fuente alternativa del municipio de Birigui; ya el máximo valor verificado fue $2,28 \mathrm{mgF} / \mathrm{L}$, siendo la muestra proveniente de Valparaíso. Hubo gran mejora en la adecuación del método en las localidades. La mayor parte de los municipios tienen fluoruro en los niveles preconizados en sus aguas de abastecimiento público. La vigilancia y el heterocontrole son importantes estrategias que auxilian el método a alcanzar su efecto preventivo.

Descriptores: Fluoruración; Salud Pública; Salud Bucal; Abastecimiento de Agua.

\section{INTRODUÇÃO}

A fluoretação das águas de abastecimento público é um método de prevenção da cárie dentária eficiente, seguro, de baixo custo, de grande abrangência, senda considerada a medida coletiva de aplicação de flúor mais relevante em Saúde Pública, devendo ser respeitadas a continuidade e regularidade das concentrações recomendadas ${ }^{1,2}$.

A adoção da fluoretação é preconizada pela Organização Mundial da Saúde (OMS), Organização PanAmericana de $S a^{2} d^{3}$, e por outras organizações de saúde nacionais e internacionais. O Centro de Prevenção e Controle de Doenças dos Estados Unidos (CDC) a julgou como um dos 10 principais êxitos da saúde pública no século $\mathrm{XX}^{4}$.

No ano de 1953, Baixo Guandu, Espírito Santo, se tornou a primeira cidade a adotar a fluoretação das águas de abastecimento público, sendo a Fundação de Serviços Especiais em Saúde Pública (FSESP), do Ministério da Saúde ${ }^{5}$ a responsável pela operacionalização do método. Posteriormente, um estudo epidemiológico realizado nesse município evidenciou que o índice CPOD de seus habitantes era muito inferior quando comparado ao restante do país, demonstrando a eficácia do método a longo prazo ${ }^{6}$.

Embora tenha sido iniciado nos anos 50 no Brasil, em 1974 a fluoretação passa a ser obrigatória em todo o território nacional, por meio da aprovação da Lei Federal $n^{\circ}$ 6.050, em todas as localidades que apresentem estações de tratamento de água $^{7}$. 
A fluoretação das águas como medidade de saúde pública foi debatida nas Conferências Nacionais de Saúde Bucal de 1986, 1993 e 2004, possuindo ainda um tópico específico nas Diretrizes da Política Nacional de Saúde Bucal, estabelecida em 2004:

Entende-se que o acesso à água tratada e fluoretada é fundamental para as condições de saúde da população. Assim, viabilizar políticas públicas que garantam a implantação da fluoretação das águas, ampliação do programa aos municípios com sistemas de tratamento é a forma mais abrangente $e$ socialmente justa de acesso ao flúor. Neste sentido, desenvolver ações intersetoriais para ampliar a fluoretação das águas no Brasil é uma prioridade governamental, garantindose continuidade e teores adequados nos termos da lei 6.050 e normas complementares, com a criação e/ou desenvolvimento de sistemas de vigilância compatíveis. A organização de tais sistemas compete aos órgãos de gestão do $\mathrm{SUS}^{8}$.

No Brasil, projetos de vigilância dos teores de flúor nas águas de abastecimento público são promovidos com o objetivo de garantir a continuidade e a segurança do método, auxiliar na manutenção dos teores preconizados do íon e assegurar à população o direito de acesso à água de qualidade. O monitoramento executado por instituição distinta daquela responsável pela adição de fluoreto foi chamado de heterocontrole 9 .

Em 1991, foi firmado um convênio entre a Faculdade de Odontologia de Araçatuba (UNESP) e a Associação Paulista de Cirurgiões-Dentistas, que objetivava o estabelecimento do "Programa de Prevenção às Doenças Bucais". Esporadicamente, a pedido da APCD, as análises eram realizadas com a água coletada em municípios do noroeste do estado de São Paulo. A partir de 2004, o projeto foi reformulado, passando então a analisar, mensal e sistematicamente, amostras de água de todos os municípios pertencentes ao Departamento Regional de Saúde-II (região de Araçatuba) da Secretaria Estadual de Saúde-SP

Para alcançar seu efeito preventivo, o método requer vigilância constante, assegurando o acesso da população à água de qualidade e com teores recomendados de flúor que garantam o máximo benefício na prevenção de cárie dentária e o risco mínimo no desenvolvimento de fluorose.

Este estudo objetivou analisar os resultados dos níveis de fluoreto das águas de abastecimento público de 40 cidades do estado de São Paulo, no período de novembro de 2004 a dezembro de 2017, e relatar as experiências do projeto da Faculdade de Odontologia de Araçatuba (Unesp) que promove o heterocontrole do flúor.

\section{MATERIAL E MÉTODO}

Trata-se de um estudo longitudinal, no qual analisouse os resultados das análises de amostras de água de 40 municípios inseridos no projeto de "Vigilância do teor de flúor das águas de abastecimento público dos municípios da região noroeste do estado de São Paulo", realizado pela Faculdade de Odontologia de Araçatuba - Unesp.

As localidades incluídas na pesquisa fazem parte da área de abrangência do Departamento Regional de Saúde II do Estado de São Paulo, sendo eles: Alto Alegre, Andradina, Araçatuba, Auriflama, Avanhandava, Barbosa, Bento de Abreu, Birigui, Bilac, Braúna, Brejo Alegre, Buritama, Castilho, Clementina, Coroados, Gabriel Monteiro, Glicério, Guaraçai, Guararapes, Guzolândia, Ilha Solteira, Itapura,
Lavínia, Lourdes, Luiziânia, Mirandópolis, Murutinga do Sul, Nova Castilho, Nova Independência, Nova Luzitânia, Penápolis, Pereira Barreto, Piacatú, Rubiácea, Santo Antônio do Aracanguá, Santópolis do Aguapeí, Sud Mennucci, Suzanápolis, Turiúba e Valparaíso.

Os pontos de coleta das amostras foram estabelecidos após análise dos mapas das redes de distribuição de água de cada localidade, baseando-se na quantidade e localização das fontes de captação de água. Para cada fonte de abastecimento de água, foram determinados 3 pontos de coleta na região abastecida por ela. Os endereços dos pontos foram selecionados por conveniência, sendo a maioria em locais públicos (escolas, praças, asilos, Unidades Básicas de Saúde, dentre outros) devido à maior facilidade de acesso. Estabeleceram-se contatos formais com os Secretários de Saúde, Coordenadores de Saúde Bucal e com os responsáveis pelo abastecimento de água de cada município.

Frascos de polietileno de $40 \mathrm{ml}$, higienizados com água deionizada com objetivo de evitar a contaminação, foram usados para armazenamento da água coletada. Os mesmos eram fechados hermeticamente, recebendo uma etiqueta de identificação, com informações referentes ao local, dia, mês, hora em que a coleta foi efetuada e o nome do responsável por ela. As amostras foram transportadas até o laboratório do Núcleo de Pesquisa em Saúde Coletiva (NEPESCO) da Faculdade de Odontologia de Araçatuba (FOA-UNESP), para que se procedessem as análises, no período máximo de 150 dias.

As análises laboratoriais foram efetuadas por meio de um analisador de íons (Model 940EA; Orion Research, Inc., Beverly, MA, USA) acoplado a um eletrodo específico para leitura do íon flúor (Model 9609BN; Orion Research, Inc.), seguindo-se a metodologia descrita por Cury ${ }^{10}$.

Valores predeterminados para as amostras com padrões que variavam de 0,1 a $1,6 \mathrm{mgF} / \mathrm{L}$ foram utilizadas para se fazer a calibração do equipamento, por meio de diluições a partir de uma solução padrão de fluoretos a 100 $\mathrm{mg} / \mathrm{L}$ (Orion, 940907). Coletou-se $1 \mathrm{ml}$ de cada um dos 5 padrões, e adicionado mais $1 \mathrm{ml}$ de "Total Ionic Strenght Adjustor Buffer" (TISAB II), uma solução tampão de ajuste de $\mathrm{pH}$, força iônica e descomplexante. Consumada a curva de calibração e estando o equipamento apto para a leitura das amostras, realizou-se a análise das mesmas, em duplicata, sendo também adicionado o composto TISAB II, na proporção de $1: 1$. Os valores verificados no analisador de íons eram em milivolts $(\mathrm{mV})$ e convertiam-se em miligramas de flúor por litro $(\mathrm{mgF} / \mathrm{L})$ ao serem repassados para uma planilha eletrônica no programa Microsoft Office Excel.

Mensalmente, os resultados das análises das amostras foram enviados aos Secretários de Saúde, Coordenadores de Saúde Bucal e responsáveis pelo tratamento de água de cada município.

Para classificação das amostras quanto ao nível de fluoreto, foi utilizada a recomendação elaborada pelo Centro Colaborador do Ministério da Saúde em Vigilância da Saúde Bucal (CECOL), a qual se baseia no princípio de maior benefício para prevenção da cárie e menor risco de desenvolver fluorose dentária, também considerando a média das temperaturas máximas anuais de cada localidade. Para a região dos municípios alvo da pesquisa, o intervalo preconizado varia de 0,55 a $0,84 \mathrm{mgF} / \mathrm{L}^{11}$.

\section{RESULTADOS}

De novembro de 2004 a dezembro de 2017 foram coletadas e analisadas, em duplicata, 34993 amostras de água (Tabela 1). Observando-se a distribuição percentual das amostras quanto aos níveis de flúor, nota-se que pouco mais da metade $(52,47 \%)$ estão dentro do intervalo que confere o máximo benefício e risco mínimo do método; aproximadamente um quarto delas $(23,68 \%)$ não atingiu o 
mínimo necessário para proporcionar seu efeito preventivo. Em relação aos valores mais elevados, que geram preocupação quanto ao desenvolvimento de fluorose, apenas uma pequena parte das amostras ultrapassaram os valores de segurança $(4,47 \%)$.

Com as Tabelas 2 a 5 é possível observar a evolução de cada um dos pontos de coleta de todos os 40 municípios do noroeste paulista englobados no projeto, por meio de suas médias anuais.
Comparando-se o primeiro ano completo do estudo com o último, em 2005, 51,75\% dos pontos de coleta possuiam teores médios de flúor entre 0,55 e $0,84 \mathrm{mgF} / \mathrm{L}$, e em 2017, 60,94\% estavam dentro desse intervalo.

O menor valor encontrado foi $0,04 \mathrm{mgF} / \mathrm{L}$, e a amostra era proveniente de uma fonte alternativa do município de Birigui; já o máximo valor verificado foi $2,28 \mathrm{mgF} / \mathrm{L}$, sendo a amostra proveniente de Valparaíso.

Tabela 1. Distribuição absoluta e percentual das amostras de água provenientes de 40 municípios do noroeste do estado de São Paulo, de novembro de 2004 a dezembro de 2017, segundo os teores de flúor

\begin{tabular}{l|r|r}
\hline $\mathbf{m g F} / \mathbf{L}$ & \multicolumn{1}{|c|}{ n } & \multicolumn{1}{c}{ \% } \\
\hline$<0,55$ & 8286 & 23,68 \\
de 0,55 a 0,84 & 18362 & 52,47 \\
de 0,85 a 1,14 & 6782 & 19,38 \\
$>1,14$ & 1563 & 4,47 \\
\hline Total & 34993 & 100 \\
\hline
\end{tabular}

Tabela 2. Médias e desvios-padrões anuais de cada ponto de coleta de água dos municípios de Alto Alegre, Andradina, Araçatuba, Auriflama, Avanhandava, Barbosa, Bento de Abreu, Bilac, Braúna, Brejo Alegre e Buritama, de 2004 a 2017

\begin{tabular}{|c|c|c|c|c|c|c|c|c|c|c|c|c|c|c|c|}
\hline Município & & & & 20 & & 20 & & 20 & & 20 & & 20 & & 20 & \\
\hline & Ponto & média & $\mathrm{dp}$ & média & $\mathrm{dp}$ & média & $d p$ & média & $d p$ & média & $d p$ & média & $\mathrm{dp}$ & média & $d p$ \\
\hline & 1 & 0,54 & 0,11 & 0,66 & 0,07 & 0,64 & 0,04 & 0,63 & 0,04 & 0,63 & 0,05 & 0,67 & 0,06 & 0,62 & 0,07 \\
\hline Alto Alegre & 2 & 0,55 & 0,12 & 0,68 & 0,08 & 0,67 & 0,06 & 0,59 & 0,08 & 0,64 & 0,05 & 0,66 & 0,08 & 0,57 & 0,12 \\
\hline & 3 & 0,55 & 0,15 & 0,68 & 0,08 & 0,67 & 0,06 & 0,61 & 0,07 & 0,66 & 0,06 & 0,66 & 0,06 & 0,61 & 0,09 \\
\hline & 1 & 0,74 & 0,15 & 0,75 & 0,22 & 0,42 & 0,26 & 0,43 & 0,34 & 0,33 & 0,03 & 0,61 & 0,41 & 0,96 & 0,40 \\
\hline Anhoradina & 2 & 0,74 & 0,15 & 0,73 & 0,23 & 0,39 & 0,32 & 0,32 & 0,09 & 0,50 & 0,39 & 0,32 & 0,03 & 0,33 & 0,04 \\
\hline & 3 & 0,74 & 0,14 & 0,82 & 0,20 & 1,14 & 0,34 & 1,01 & 0,31 & 0,83 & 0,37 & 0,60 & 0,40 & 0,52 & 0,49 \\
\hline & 1 & 0,73 & 0,03 & 0,66 & 0,09 & 0,75 & 0,04 & 0,77 & 0,02 & 0,78 & 0,05 & 0,77 & 0,03 & 0,77 & 0,02 \\
\hline & 2 & 0,74 & 0,00 & 0,66 & 0,09 & 0,77 & 0,05 & 0,78 & 0,02 & 0,77 & 0,06 & 0,77 & 0,03 & 0,75 & 0,06 \\
\hline & 3 & 0,59 & 0,14 & 0,65 & 0,09 & 0,74 & 0,05 & 0,75 & 0,08 & 0,75 & 0,07 & 0,75 & 0,06 & 0,70 & 0,11 \\
\hline Araçatuba & 4 & 0,63 & 0,09 & 0,51 & 0,11 & 0,66 & 0,07 & 0,84 & 0,05 & 0,71 & 0,22 & 0,85 & 0,04 & 0,85 & 0,03 \\
\hline & 5 & 0,61 & 0,09 & 0,50 & 0,10 & 0,66 & 0,07 & 0,88 & 0,19 & 0,69 & 0,22 & 0,84 & 0,03 & 0,85 & 0,02 \\
\hline & 6 & 0,57 & 0,07 & 0,51 & 0,11 & 0,67 & 0,08 & 0,82 & 0,05 & 0,77 & 0,11 & 0,92 & 0,28 & 0,85 & 0,03 \\
\hline & 7 & 0,63 & 0,14 & 0,42 & 0,12 & 0,60 & 0,11 & 0,75 & 0,08 & 0,82 & 0,08 & 0,67 & 0,06 & 0,60 & 0,13 \\
\hline & 8 & 0,58 & 0,15 & 0,44 & 0,13 & 0,56 & 0,06 & 0,78 & 0,08 & 0,79 & 0,06 & 0,67 & 0,06 & 0,59 & 0,17 \\
\hline & 9 & 0,68 & 0,06 & 0,44 & 0,14 & 0,56 & 0,07 & 0,76 & 0,10 & 0,75 & 0,10 & 0,66 & 0,06 & 0,57 & 0,11 \\
\hline & 1 & 0,61 & 0,12 & 0,41 & 0,32 & 0,57 & 0,16 & 0,70 & 0,03 & 0,65 & 0,04 & 0,66 & 0,03 & 0,66 & 0,02 \\
\hline Auriflama & 2 & 0,61 & 0,12 & 0,45 & 0,31 & 0,62 & 0,04 & 0,69 & 0,03 & 0,65 & 0,04 & 0,67 & 0,03 & 0,67 & 0,03 \\
\hline & 3 & 0,62 & 0,12 & 0,41 & 0,33 & 0,57 & 0,16 & 0,69 & 0,02 & 0,65 & 0,05 & 0,67 & 0,03 & 0,67 & 0,02 \\
\hline & 1 & 0,90 & 0,16 & 0,65 & 0,24 & 0,47 & 0,00 & 1,50 & 0,00 & 0,75 & 0,02 & 0,66 & 0,12 & 0,51 & 0,30 \\
\hline Avanhandava & 2 & 0,89 & 0,16 & 0,66 & 0,26 & 0,49 & 0,00 & 1,60 & 0,00 & 0,83 & 0,11 & 0,68 & 0,05 & 0,53 & 0,33 \\
\hline & 3 & 0,89 & 0,14 & 0,66 & 0,09 & 0,49 & 0,00 & 1,70 & 0,0 & 0,71 & 0,0 & 0,6 & 0, & 0 & 0,25 \\
\hline & 1 & 0,05 & 0,02 & 0,43 & 0,56 & 0,80 & 0,44 & 0,74 & 0,11 & 0,89 & 0,30 & 0,85 & 0,14 & 0,55 & 0,23 \\
\hline & 2 & 0,46 & 0,09 & 0,58 & 0,11 & 0,75 & 0,06 & 0,74 & 0,09 & 0,71 & 0,05 & 0,83 & 0,08 & 0,70 & 0,09 \\
\hline & 3 & 0,49 & 0,11 & 0,57 & 0,11 & 0,73 & 0,06 & 0,75 & 0,08 & 0,71 & 0,05 & 0,84 & 0,07 & 0,70 & 0,09 \\
\hline & 4 & 0,48 & 0,09 & 0,59 & 0,10 & 0,74 & 0,06 & 0,75 & 0,08 & 0,70 & 0,05 & 0,88 & 0,24 & 0,71 & 0,09 \\
\hline Barbosa & 5 & 0,49 & 0,10 & 0,58 & 0,11 & 0,74 & 0,08 & 0,75 & 0,09 & 0,73 & 0,0 & 0,86 & 0,1 & 0,69 & 0,09 \\
\hline & 6 & $\star *$ & * & 0,71 & 0,04 & 0,75 & 0,06 & 0,75 & 0,08 & 0,72 & 0,04 & 0,84 & 0,09 & 0,71 & 0,09 \\
\hline & 7 & * & * & 1,02 & 0,49 & 0,71 & 0,42 & 0,68 & 0,14 & 0,89 & 0,31 & 0,78 & 0,19 & 0,83 & 0,26 \\
\hline & 8 & * & * & 0,72 & 0,04 & 0,86 & 0,31 & 0,75 & 0,08 & 0,70 & 0,06 & 0,84 & 0,08 & 0,72 & 0,10 \\
\hline & 9 & * & * & 0,71 & 0,03 & 0,70 & 0,11 & 0,75 & 0,08 & 0,70 & 0,05 & 0,85 & 0,08 & 0,70 & 0,09 \\
\hline & 1 & 0,55 & 0,18 & 0,60 & 0,09 & 0,66 & 0,07 & 0,63 & 0,20 & 0,57 & 0,0 & 0,55 & 0, & 0,72 & \\
\hline Bento de Abreu & 2 & 0,52 & 0,15 & 0,60 & 0,09 & 0,61 & 0,17 & 0,69 & 0,15 & 0,57 & 0,09 & 0,58 & 0,11 & 0,73 & 0,13 \\
\hline & 3 & 0,53 & 0,14 & 0,59 & 0,10 & 0,68 & 0,12 & 0,65 & 0,18 & 0,57 & 0,08 & 0,59 & 0,13 & 0,72 & 0,13 \\
\hline & 1 & 0,08 & 0,06 & 0,45 & 0,30 & 0,74 & 0,11 & & & * & * & * & * & * & * \\
\hline & 2 & 0,10 & 0,04 & 0,52 & 0,37 & 0,75 & 0,11 & * & * & * & * & * & * & * & * \\
\hline & 3 & 0,19 & 0,04 & 0,39 & 0,2 & 0,77 & 0 & * & * & * & * & * & * & * & * \\
\hline Bilac & 4 & * & & 0,69 & 0,38 & 0,92 & 0,06 & * & * & * & * & * & * & * & * \\
\hline Bilac & 5 & * & * & 0,84 & 0,32 & 1,04 & 0,33 & * & * & * & * & * & * & * & * \\
\hline & 6 & * & * & 0,84 & 0,12 & 1,24 & 0,19 & * & * & * & * & * & * & * & * \\
\hline & 7 & * & * & 0,55 & 0,34 & 0,45 & 0,31 & * & * & * & * & * & * & * & * \\
\hline & 8 & * & * & 0,57 & & & & * & * & * & * & * & & * & \\
\hline & 9 & * & * & 0,74 & & & & * & * & * & * & * & * & * & * \\
\hline & 10 & * & * & 0,65 & 0,28 & 0,73 & 0,71 & * & * & * & * & * & * & * & * \\
\hline & 11 & * & * & 0,76 & 0,0 & 0,99 & 0,46 & * & * & * & * & * & * & * & * \\
\hline & 12 & * & * & 0,77 & 0,07 & 0,68 & 0,34 & * & * & * & * & * & * & * & * \\
\hline & 1 & 0,06 & 0,01 & 0,06 & 0,0 & 0,0 & 0,02 & 0,56 & 0,21 & 0,61 & 0,22 & 0,51 & 0,18 & 0,47 & 0,18 \\
\hline & 2 & 0,06 & 0,01 & 0,06 & & $0, C$ & & 55 & 0,28 & 0,68 & & 0,90 & & 0,81 & 09 \\
\hline Braúna & 3 & 0,06 & 0,01 & 0,05 & 0,02 & 0,07 & 0,01 & 0,62 & 0,30 & 0,60 & 0,25 & 0,68 & 0,11 & 1,13 & 0,46 \\
\hline & 4 & 0,07 & 0,01 & 0,05 & 0,02 & 0,07 & 0,01 & 0,58 & 0,29 & 0,60 & 0,23 & 0,69 & 0,14 & 1,09 & 0,40 \\
\hline & 5 & $*$ & & 0,05 & 0,02 & 0,07 & 0,01 & 0,56 & 0,22 & 0,67 & 0,14 & 0,52 & 0,18 & 0,52 & 0,13 \\
\hline & 6 & * & * & 0,05 & 0 & 0,07 & & & 0,22 & & & & & & \\
\hline & 7 & * & * & 0,04 & & & & & & & & & & & \\
\hline & 8 & * & * & 0,04 & 0,02 & 0,07 & 0,02 & 0,55 & 0,27 & 0,75 & 0,13 & 0,89 & 0,25 & 0,76 & 0,16 \\
\hline & 9 & & & 0,05 & 0,0 & 0,07 & 0,02 & 0,56 & 0,29 & 0,75 & 0, & 0,89 & 0,24 & 0 & \\
\hline & 1 & 0,56 & 0,04 & 0,5 & 0,0 & & 0 & & 0,0 & & & & & & \\
\hline Brejo Alegre & 2 & 0, & 0,05 & 0,6 & $0, C$ & 0, & 0,1 & 0,7 & 0,05 & 0,70 & 0 , & & & & \\
\hline & 3 & 0 & 0, & 0,5 & & & & & & & & & & & \\
\hline & 1 & 0,12 & 0,02 & 0,08 & 0,0 & 0,5 & 0,29 & 0,59 & 0,29 & 0,44 & 0,2 & 0,65 & 0,17 & 0 , & 0,23 \\
\hline & 2 & 0,10 & 0,01 & 0,09 & $0, c$ & 0,5 & 0,41 & 0,54 & 0,32 & & 0,3 & & & & \\
\hline & 3 & & 0,0 & & 0,0 & & & & 0,2 & & & & & & \\
\hline Buritama & 4 & 0,09 & 0,01 & 0,0 & $0, C$ & 0 & & & 0,2 & & & & & & \\
\hline & 5 & 0,11 & 0,01 & 0,09 & 0,0 & 0 & 0 & 0, & 0, & & & & & & \\
\hline & 6 & & . & 0,05 & 0,01 & 0,6 & 0,3 & & 0, & & & & 0 & & \\
\hline & 7 & * & * & 0,0 & * & 0, & & 0,5 & 0,25 & & & & & & \\
\hline & 8 & * & * & * & * & & & & & & & & & & \\
\hline & 9 & & & & * & 0,93 & 0,0 & & & & & & & & 0,1 \\
\hline & 10 & * & * & * & * & 0,04 & & & & & & & & & \\
\hline & 11 & * & * & * & * & & & & & & & & & & \\
\hline & 12 & * & * & * & * & 0, & & & 0,3 & & & & & & \\
\hline & & & & & * & & & & & & & & & & \\
\hline & 14 & & & & * & 0,5 & 0,00 & & 0,2 & 0,37 & & 0 & 0,2 & & \\
\hline & 15 & * & * & * & * & 0,51 & 0,00 & 0, & 0,2 & 0,3 & & & 0 & & \\
\hline & 16 & & & & & 0,8 & 0,0 & & & & & & & & \\
\hline & 17 & & & & & 0, & 0,0 & & 0 & & & & & & \\
\hline & & & & & * & 0,63 & 0,00 & & 0 & & & & & & \\
\hline & 1 & & & & * & & * & 0,20 & 0,18 & 0,13 & 0,01 & 0,22 & 0,18 & 0,12 & 0,04 \\
\hline & 20 & * & * & * & * & * & * & 0,21 & 0,21 & 0,18 & 0,18 & 0,13 & 0,03 & 0,14 & 0,01 \\
\hline & 21 & * & * & * & & * & & 0,19 & 0,16 & 0,1 & & & 0, & 0, & \\
\hline & 2 & & * & * & * & & & & 0 & & & & 0 & & \\
\hline & 23 & & * & & * & * & * ${ }^{*}$ & 0,43 & 0,23 & 0,30 & 0,28 & 0,66 & 0,22 & 0,62 & 0,13 \\
\hline & 24 & * & * & * & * & * & * & 0,46 & 0,25 & 0,28 & 0,23 & 0,66 & 0,23 & 0,66 & 0,13 \\
\hline
\end{tabular}


Tabela 3. Médias e desvios-padrões anuais de cada ponto de coleta de água do município de Birigui de 2004 a 2017

\begin{tabular}{|c|c|c|c|c|c|c|c|c|c|c|c|c|c|c|c|c|c|c|c|c|c|c|c|c|c|c|c|c|c|}
\hline \multirow[t]{2}{*}{ Município } & \multirow[b]{2}{*}{ Ponto } & \multicolumn{2}{|c|}{2004} & \multicolumn{2}{|c|}{2005} & \multicolumn{2}{|c|}{2006} & \multicolumn{2}{|c|}{2007} & \multicolumn{2}{|c|}{2008} & \multicolumn{2}{|c|}{2009} & \multicolumn{2}{|c|}{2010} & \multicolumn{2}{|c|}{2011} & \multicolumn{2}{|c|}{2012} & \multicolumn{2}{|c|}{2013} & 20 & & 20 & & 20 & & 20 & \\
\hline & & média & $\mathrm{dp}$ & média & $\mathrm{dp}$ & média & $\mathrm{dn}$ & média & & média & & média & & média & & média & & média & & média & & média & $\mathrm{dn}$ & média & $\mathrm{dp}$ & média & & média & \\
\hline & 1 & 0,08 & 0.06 & 0,31 & 0.31 & 0.62 & 0,20 & 0,54 & 0.02 & 0,76 & 0.13 & 0,78 & 0,10 & 0,70 & 0,16 & 0,87 & 0,14 & 0,89 & 0,10 & 0,82 & 0,13 & 0,71 & 0.10 & 0.67 & 0.17 & 0.78 & 0,08 & 0.45 & 0,36 \\
\hline & 2 & 0,10 & 0,04 & 0,51 & 0,15 & 0,41 & 0,30 & 0,54 & 0,02 & 0,76 & 0,07 & 0,76 & 0,10 & 0,68 & 0,15 & 0,85 & 0,12 & $\begin{array}{l}0,05 \\
1,00\end{array}$ & 0,18 & 0,80 & 0,10 & 0,91 & 0,22 & 0,67 & 0,14 & 0,77 & 0,10 & 0,49 & $\begin{array}{l}0,37 \\
0,37\end{array}$ \\
\hline & 3 & 0,19 & 0,04 & 0,76 & 0,28 & 0,88 & 0,34 & 0,55 & 0,03 & 0,73 & 0,09 & 0,76 & 0,10 & 0,69 & 0,15 & 0,84 & 0,14 & 0,95 & 0,18 & 0,83 & 0,09 & 0,96 & 0,26 & 0,73 & 0,16 & 0,77 & 0,07 & 0,50 & 0,37 \\
\hline & 4 & 0.13 & 0.03 & 0.54 & 0.32 & 0.99 & 0.15 & 0.71 & 0.06 & 1.14 & 0.03 & 1.12 & 0.03 & 110 & 0.03 & 1.13 & 0.02 & 120 & 0.07 & 120 & 0.10 & 1.10 & 0.17 & 1.01 & 0.07 & 105 & 0.06 & 0.60 & 0.54 \\
\hline & 5 & 0,59 & 0,05 & 0,55 & 0,08 & 0,55 & 0,11 & 0,72 & 0,06 & 1,14 & 0,03 & 1,11 & 0,03 & 1,11 & 0,03 & 1,13 & 0,02 & 1,20 & 0,04 & 1,21 & 0,09 & 1,07 & 0,22 & 1,00 & 0,09 & 1,07 & 0,07 & 0,60 & 0,54 \\
\hline & 6 & $*$ & & 0,73 & 0,18 & 0,82 & 0,12 & 0,70 & 0,06 & 1,08 & 0,09 & 1,08 & 0,10 & 1,11 & 0,04 & 1,06 & 0,21 & 1,08 & 0,15 & 1,16 & 0,09 & 1,13 & 0,15 & 1,02 & 0,09 & 1,11 & 0,05 & 0,61 & 0,51 \\
\hline & 7 & * & * & 0,93 & 0,14 & 0,99 & 0,06 & 0,42 & 0,38 & 1,06 & 0,20 & 1,06 & 0,10 & 1,06 & 0,12 & 1,05 & 0,19 & 1,11 & 0,12 & 1,03 & 0,12 & 0,84 & 0,23 & 0,73 & 0,12 & 0,88 & 0,12 & 0,55 & 0,43 \\
\hline & 8 & * & * & 0,91 & 0,26 & 1,02 & 0,03 & 0,42 & 0,39 & 0,82 & 0,18 & 0,72 & 0,12 & 0,69 & 0,13 & 0,84 & 0,20 & 1,04 & 0,12 & 1,03 & 0,13 & 0,97 & 0,34 & 0,77 & 0,12 & 0,84 & 0,13 & 0,55 & 0,40 \\
\hline & 9 & * & * & 0,64 & 0,20 & 0,49 & 0,09 & 0,41 & 0,39 & 0,89 & 0,16 & 0,84 & 0,16 & 0,89 & 0,11 & 0,97 & 0,13 & 0,99 & 0,13 & 0,80 & 0,05 & 0,92 & 0,24 & 0,80 & 0,15 & 0,76 & 0,08 & 0,50 & 0,40 \\
\hline & 10 & * & * & 0,66 & 0,25 & 0,59 & 0,16 & 0,70 & 0,11 & 1,12 & 0,04 & 1,09 & 0,03 & 1,06 & 0,08 & 1,10 & 0,03 & 1,18 & 0,12 & 1,16 & 0,08 & 1,20 & 0,11 & 1,02 & 0,10 & 1,10 & 0,04 & 0,60 & 0,55 \\
\hline & 11 & * & * & 0,38 & 0,11 & 0,72 & 0,18 & 0,70 & 0,10 & 1,1 & 0,0 & 1,09 & 0,02 & 1,08 & 0,02 & 1,06 & 0,14 & 1, & 0,0 & 1,14 & 0,0 & & 0,14 & & 0,10 & 1,12 & 0,13 & 61 & 0,53 \\
\hline & 12 & * & * & 0,61 & 0,02 & 0,39 & 0,27 & 0,87 & 0,07 & 1,11 & 0,04 & 1,09 & 0,03 & 1,08 & 0,03 & 1,05 & 0,14 & 1,17 & 0,03 & 1,17 & 0,09 & 1,11 & 0,18 & 1,03 & 0,10 & 1,16 & 0,24 & 0,62 & 0,52 \\
\hline & 13 & * & * & 0,68 & 0,06 & 0,90 & 0,41 & 0,12 & 0,02 & 0,99 & 0,07 & 1,00 & 0,09 & 0,99 & 0,08 & 1,00 & 0,14 & 1,10 & 0,27 & 0,91 & 0,12 & 1,09 & 0,16 & 1,01 & 0,13 & 0,90 & 0,13 &, 58 & 0,45 \\
\hline & 14 & * & * & 0,61 & 0,38 & 0,40 & 0,24 & 0,06 & 0,01 & 0,98 & 0,14 & 0,91 & 0,11 & 0,80 & 0,14 & 1,00 & 0,20 & 0,96 & 0,09 & 0,95 & 0,12 & 0,88 & 0,25 & 0,83 & 0,12 & 0,91 & 0,15 & 0,54 & 0,41 \\
\hline & 15 & * & * & 0,66 & 0,23 & 0,59 & 0,12 & 0,10 & 0,02 & 0,87 & 0,18 & 0,89 & 0,12 & 0,87 & 0,14 & 0,98 & 0,11 & 1,09 & 0,12 & 0,77 & 0,09 & & 0,21 & & 0,14 & & 0,14 & & 0,42 \\
\hline & 16 & * & * & & & & & 0,03 & 0,01 & 0,81 & 0,1 & & 0,28 & 0,78 & 0,23 & 1,18 & 0,4 & 1, & 0 & 0,67 & 0, & & 0,2 & & & & & & 0,39 \\
\hline & 17 & * & * & * & * & * & * & 0,04 & 0,01 & 0,82 & 0,15 & 0,79 & 0,29 & 0,75 & 0,22 & 1,16 & 0,42 & 1,14 & 0,24 & 0,65 & 0,33 & 0,83 & 0,21 & 0,70 & 0,09 & 0,88 & 0,11 & 0,56 & 0,38 \\
\hline & 18 & * & * & * & * & * & * & 1,12 & 0,01 & 0,80 & 0,15 & 0,79 & 0,29 & 0,75 & 0,23 & 1,08 & 0,43 & 1,10 & 0,25 & 0,64 & 0,34 & 0,80 & 0,22 & 0,72 & 0,10 & 0,87 & 0,10 & 0,55 & 0,36 \\
\hline & 19 & * & * & * & * & * & * & 1,14 & 0,01 & 0,90 & 0,25 & 0,67 & 0,20 & 0,73 & 0,25 & 0,72 & 0,42 & 0,80 & 0,33 & 0,58 & 0,19 & 0,73 & 0,19 & 0,71 & 0,08 & 0,73 & 0,10 & 0,47 & 0,28 \\
\hline & 20 & * & * & * & * & * & * & 1,14 & 0,01 & 0,90 & 0,25 & 0,66 & 0,20 & 0,76 & 0,26 & 0,72 & $\begin{array}{l}0,4< \\
0,41\end{array}$ & 0,79 & 0,13 & 0,58 & 0,20 & 0,77 & 0,22 & 0,71 & 0,08 & 0,73 & 0,08 & 0,45 & $\begin{array}{l}0,<0 \\
0,29\end{array}$ \\
\hline & 21 & * & * & * & * & * & * & 0,74 & 0,04 & 0,91 & 0, & 0,66 & 0,20 & 0,76 & 0,26 & 0,61 & 0,42 & & & 0,60 & 0. & & 0,24 & & & 0,71 & & & 0,27 \\
\hline & 22 & * & * & * & * & * & * & 0,74 & 0,06 & 0,67 & 0,15 & 0,80 & 0,22 & 0,70 & 0,11 & 0,70 & 0,33 & 0,79 & 0,18 & 0,63 & 0,17 & 0,80 & 0,30 & 0,75 & 0,10 & 0,69 & 0,09 & 0,46 & $\begin{array}{l}0,29 \\
0,21\end{array}$ \\
\hline & 23 & * & * & * & * & * & * & 0,72 & 0,02 & 0,65 & 0,14 & 0,79 & 0,22 & 0,70 & 0,11 & 0,70 & 0,35 & 0,78 & 0,23 & 0,63 & 0,17 & 0,68 & 0,27 & 0,71 & 0,10 & 0,68 & 0,10 & 0,45 & 0,27 \\
\hline & 24 & * & * & * & * & * & * & 0,03 & 0,01 & 0,67 & 0,14 & 0,79 & 0,22 & 0,70 & 0,11 & 0,70 & 0,34 & 0,79 & 0,24 & 0,62 & 0,18 & 0,77 & 0,23 & 0,76 & 0,11 & 0,68 & 0,10 & 0,46 & 0,28 \\
\hline & 25 & * & * & * & * & * & * & 0,79 & 0.33 & 0,72 & 0,10 & 0,68 & 0,08 & 0,80 & 0,28 & 0,91 & 0,18 & 0,87 & 0,2 & 0,69 & 0,14 & & 0,23 & & 0,13 & 0,73 & & & 0,33 \\
\hline & $\begin{array}{l}25 \\
26\end{array}$ & * & 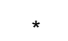 & * & * & * & & 0,38 & 0,1 & & 0, & $\begin{array}{l}0,60 \\
0,68\end{array}$ & 0,08 & $\begin{array}{l}0,00 \\
0,79\end{array}$ & 0, & $\begin{array}{l}0, \\
0,\end{array}$ & & & & & 0, & & $\begin{array}{l}0,6 \\
0,2\end{array}$ & & 0 & $\begin{array}{l}0,67 \\
0,61\end{array}$ & & & $\begin{array}{l}0,35 \\
0,35\end{array}$ \\
\hline & 27 & * & * & * & * & * & * & 0,39 & 0,17 & 0,73 & 0,0 & 0,68 & 0,08 & 0,79 & 0,29 & 0,93 & 0,21 & 0,87 & 0, & 0,68 & 0,18 & & 0,29 & 0,88 & 0,04 & 0,67 & 0,11 & 48 & 0,36 \\
\hline & 28 & * & * & * & * & * & * & 0,39 & 0,17 & 0,70 & 0,1 & 0,81 & 0,25 & 0,81 & 0,20 & 0,59 & 0,50 & 0,64 & 0, & 0,63 & 0,27 & 0,89 & 0,19 & 0,79 & 0,10 & 0,74 & 0,04 & 0,49 & 0,28 \\
\hline & 29 & * & * & * & * & * & * & 0,68 & 0,11 & 0,7 & 0 & 0,82 & 0,25 & 0,81 & 0,20 & 0,60 & 0,47 & & 0 & 0,64 & 0 & & & & & 0,74 & & & 0,32 \\
\hline & 30 & * & * & * & * & * & * & 0,70 & 0,11 & 0,82 & 0 & 0,84 & 0,25 & 0,80 & 0,20 & 0,59 & 0, & & 0,2 & 0 , & 0, & & 0,19 & & 0,18 & 0,68 & 0,16 & & 0,29 \\
\hline & 31 & * & * & * & * & * & * & 0,69 & 0,1 & 0, & 0, & & 0 & $0, \varepsilon$ & $\begin{array}{l}0,17\end{array}$ & 0, & 0, & & 0 & 1,0 & 0 & & 0,16 & & $\begin{array}{l}0,12 \\
0,12\end{array}$ & $\begin{array}{l}0,00 \\
0,91\end{array}$ & 0,25 & & $\begin{array}{l}0,29 \\
0,41\end{array}$ \\
\hline & 32 & * & * & * & * & * & * & 0,69 & 0,0 & & 0 & & 0 & 0,87 & 0 , & 0,9 & 0 , & & & 1,00 & & & 0 & & & 0,94 & & & 0,42 \\
\hline & 33 & * & * & * & * & * & * & 0,88 & 0,12 & 0,63 & 0,1 & $\begin{array}{l}0,01 \\
0,85\end{array}$ & 0,16 & 0,85 & 0,17 & 0,91 & 0,16 & 0,8 & 0, & 1,06 & 0,15 & 1,0 & $\begin{array}{l}0,<0 \\
0,16\end{array}$ & 0 , & 0,02 & $\begin{array}{l}0,94 \\
0,9\end{array}$ & $\begin{array}{l}0,24 \\
0,21\end{array}$ & & $\begin{array}{l}0,43 \\
0,43\end{array}$ \\
\hline & 34 & * & * & * & & * & * & 0,97 & 0,11 & & 0 , & & 0, & & 0 , & 1, & & & & 0,70 & & & & & & 0,73 & & & 0,35 \\
\hline & 35 & * & * & * & * & * & * & 0,91 & 0,09 & 0,64 & 0,24 & 0,83 & 0,14 & 0,94 & 0,17 & 1,06 & 0,19 & 0,85 & 0,04 & 0,67 & 0,26 & 0,87 & 0,26 & 0,74 & 0,16 & 0,73 & 0,09 & 0,49 & 0,36 \\
\hline & $\begin{array}{l}50 \\
36\end{array}$ & * & * & * & * & * & * & & & $\begin{array}{l}0,64 \\
0,68\end{array}$ & $\begin{array}{l}0,24 \\
0,20\end{array}$ & $\begin{array}{l}0,03 \\
\end{array}$ & 0,14 & $\begin{array}{l}0,94 \\
\end{array}$ & 0,17 & $\begin{array}{l}1,00 \\
1,08\end{array}$ & 0,20 & $\begin{array}{l}0,05 \\
0,84\end{array}$ & $\begin{array}{l}0,0 \\
0,0\end{array}$ & 0,66 & $\begin{array}{l}0,20 \\
0,20\end{array}$ & & $\begin{array}{l}0,20 \\
0,27\end{array}$ & $\begin{array}{l}0,74 \\
\end{array}$ & 0,15 & 0,76 & 0,10 & $\begin{array}{l}0,45 \\
0,50\end{array}$ & $\begin{array}{l}0,00 \\
0,36\end{array}$ \\
\hline & 37 & * & * & * & * & * & * & 0,91 & 0,14 & 0 , & 0, & & 0, & 0, & 0 , & 0, & & & & $0, \varepsilon$ & 0 & & 0,14 & & & 0,80 & & & 0,44 \\
\hline & 38 & * & * & * & * & * & * & 0,89 & 0,1 & 0 & 0, & & 0, & $\begin{array}{l}0,90 \\
0\end{array}$ & 0, & 0, & & & & $\begin{array}{l}0,89 \\
\end{array}$ & & & & & & $\begin{array}{l}0,79 \\
\end{array}$ & & & $\begin{array}{l}0,44 \\
0,44\end{array}$ \\
\hline & 3 & * & & & & & * & & & & & & 0, & & 0,0 & 0,99 & & & & 0,90 & 0 & & & & 0,02 & 0,81 & 0,08 & 50 & 0,42 \\
\hline & 40 & * & * & * & * & * & * & 0,74 & 0,02 & 1,12 & 0,05 & 1,02 & 0,18 & 0,72 & 0,37 & 0,48 & 0,28 & 0,37 & 0,21 & 0,22 & 0,16 & 0,55 & 0,34 & 0,59 & 0,27 & 0,73 & 0,09 & 0,36 & 0,19 \\
\hline & 41 & * & * & * & * & * & * & 0,64 & 0,08 & 0,11 & 0,01 & 0,11 & 0,01 & & & & & 0, & 0,02 & & & 0,12 & 0,03 & 0,11 & 0,03 & 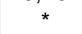 & & & \\
\hline & 42 & * & * & * & $*$ & * & * & 1,11 & 0,00 & 0,06 & 0,01 & 0,06 & 0,00 & 0,08 & 0,02 & 0,09 & 0,03 & 0,12 & 0,01 & 0,16 & 0,07 & 0,12 & 0,04 & 0,14 & 0,01 & 0,15 & 0,05 & 0,08 & 0,06 \\
\hline & 43 & * & * & * & * & * & * & 1,13 & 0,02 & 0,10 & 0,01 & 0,11 & 0,02 & 0,12 & 0,02 & 0,13 & 0,04 & 0,17 & 0,06 & 0,16 & 0,05 & & & 0,13 & 0,00 & 0,19 & 0,10 & 0,10 & 0,07 \\
\hline
\end{tabular}

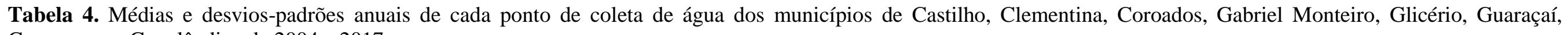
Guararapes e Guzolândia, de 2004 a 2017

\begin{tabular}{|c|c|c|c|c|c|c|c|c|c|c|c|c|c|c|c|c|c|c|c|c|c|c|c|c|c|c|c|c|c|}
\hline Município & Ponto & média & & $\begin{array}{l}20 \\
\text { média }\end{array}$ & $5 \mathrm{dp}$ & $\begin{array}{l}20 \\
\text { média }\end{array}$ & & $\begin{array}{l}20 \\
\text { média }\end{array}$ & & $\begin{array}{l}2{ }^{2} \\
\text { média }\end{array}$ & & $\begin{array}{l}20 \\
\text { média }\end{array}$ & & $\begin{array}{r}20 \\
\text { média }\end{array}$ & ${ }^{0}{ }_{\mathrm{dp}}$ & $\begin{array}{r}20 \\
\text { média }\end{array}$ & & média & & $\begin{array}{l}20 \\
\text { média }\end{array}$ & & $\begin{array}{l}20 \\
\text { média }\end{array}$ & & $\begin{array}{r}20 \\
\text { média }\end{array}$ & & $\begin{array}{l}20 \\
\text { média }\end{array}$ & $\mathrm{dp}$ & $\begin{array}{r}20 \\
\text { média }\end{array}$ & \\
\hline & 1 & 0,41 & 0,00 & 0,56 & 0,15 & 0,71 & 0,27 & 0,75 & 0,39 & 0,76 & 0,14 & 0,78 & 0,19 & 0,82 & 0,35 & 0,86 & 0,25 & 0,64 & 0,14 & 0,72 & 0,07 & 0,72 & 0,14 & 0,99 & 0,17 & 0,89 & 0,39 & 0,50 & 0,34 \\
\hline & 2 & 0,80 & 0,01 & 0,60 & 0,09 & 0,74 & 0,27 & 0,64 & 0,38 & 0,78 & 0,15 & 0,68 & 0,10 & 0,63 & 0,03 & 0,67 & 0,18 & 0,67 & 0,11 & 0,90 & 0,19 & 0,91 & 0,35 & 1,05 & 0,53 & 0,73 & 0,09 & 0,53 & 0,34 \\
\hline Castilho & 3 & 0,56 & 0,00 & 0,71 & 0,29 & 0,74 & 0,28 & 0,81 & 0,55 & 0,76 & 0,17 & 0,64 & 0,13 & 0,63 & 0,04 & 0,64 & 0,20 & 0,65 & 0,11 & 0,78 & 0,20 & 0,92 & 0,75 & 1,01 & 0,31 & 0,73 & 0,10 & 0,53 & 0,33 \\
\hline & 4 & 0,34 & 0,03 & 0,70 & 0,25 & 0,71 & 0,30 & 0,65 & 0,23 & 0,81 & 0,23 & 0,86 & 0,15 & 0,62 & 0,33 & 0,67 & 0,24 & 0,51 & 0,16 & 0,66 & 0,26 & 0,68 & 0,13 & 0,72 & 0,20 & 0,75 & 0,11 & 0,42 & 0,26 \\
\hline & 5 & 0,36 & 0,04 & 0,69 & 0,25 & 0,72 & 0,30 & 0,65 & 0,24 & 0,80 & 0,22 & 0,86 & 0,15 & 0,63 & 0,35 & 0,67 & 0,26 & 0,54 & 0,20 & 0,63 & 0,15 & 0,72 & 0,16 & 0,71 & 0,19 & 0,76 & 0,09 & 0,42 & 0,27 \\
\hline & 6 & 0,39 & 0,01 & 0,66 & 0,25 & 0,73 & 0,28 & 0,64 & 0,25 & 0,82 & 0,24 & 0,82 & 0,14 & 0,60 & 0,35 & 0,75 & 0,29 & 0,55 & 0,11 & 0,62 & 0,15 & 0,72 & 0,14 & 0,71 & 0,20 & 0,77 & 0,19 & 0,43 & 0,27 \\
\hline & 7 & * & * & 0,59 & 0,10 & 0,73 & 0,28 & 0,72 & 0,38 & 0,78 & 0,14 & 0,73 & 0,16 & 0,68 & 0,16 & 0,69 & 0,16 & 0,65 & 0,10 & 0,74 & 0,10 & 0,74 & 0,12 & 0,66 & 0,19 & 0,76 & 0,24 & 0,43 & 0,29 \\
\hline & 8 & * & * & 0,59 & 0,11 & 0,74 & 0,28 & 0,87 & 0,40 & 0,71 & 0,16 & 0,65 & 0,14 & 0,56 & 0,12 & 0,71 & 0,19 & 0,73 & 0,15 & 0,75 & 0,21 & 0,73 & 0,14 & 0,91 & 0,16 & 0,71 & 0,16 & 0,46 & 0,31 \\
\hline & 9 & * & * & 0,57 & 0,12 & 0,73 & 0,30 & 0,60 & 0,16 & 0,81 & 0,13 & 0,80 & 0,20 & 0,70 & 0,14 & 0,68 & 0,16 & 0,62 & 0,17 & 0,75 & 0,11 & 0,71 & 0,13 & 0,78 & 0,21 & 0,74 & 0,27 & 0,44 & 0,29 \\
\hline & 10 & * & * & 0,57 & 0,15 & 0,75 & 0,28 & 0,68 & 0,38 & 0,78 & 0,15 & 0,65 & 0,12 & 0,64 & 0,03 & 0,64 & 0,19 & 0,66 & 0,15 & 0,69 & 0,18 & 0,89 & 0,34 & 0,91 & 0,18 & 0,71 & 0,14 & 0,47 & 0,31 \\
\hline & 11 & * & * & 0,53 & 0,09 & 0,74 & 0,28 & 0,63 & 0,35 & 0,80 & 0,15 & 0,67 & 0,09 & 0,62 & 0,03 & 0,54 & 0,18 & 0,57 & 0,10 & 0,71 & 0,21 & 0,83 & 0,30 & 0,91 & 0,22 & 0,72 & 0,13 & 0,45 & 0,29 \\
\hline & 12 & * & * & 0,53 & 0,10 & 0,74 & 0,28 & 0,54 & 0,14 & 0,79 & 0,16 & 0,65 & 0,11 & 0,64 & 0,03 & 0,54 & 0,17 & 0,60 & 0,10 & 0,75 & 0,27 & 0,81 & 0,31 & 0,85 & 0,11 & 0,70 & 0,13 & 0,44 & 0,29 \\
\hline & 13 & * & * & 0,53 & 0,09 & 0,75 & 0,28 & 0,70 & 0,39 & 0,75 & 0,14 & 0,67 & 0,10 & 0,62 & 0,06 & 0,63 & 0,21 & 0,64 & 0,10 & 0,70 & 0,13 & 0,79 & 0,20 & 0,90 & 0,15 & 0,74 & 0,11 & 0,44 & 0,31 \\
\hline & 14 & * & * & 0,53 & 0,10 & 0,75 & 0,29 & 0,96 & 0,54 & 0,71 & 0,16 & 0,62 & 0,13 & 0,58 & 0,14 & 0,64 & 0,21 & 0,72 & 0,11 & 0,71 & 0,21 & 0,76 & 0,25 & 0,87 & 0,14 & 0,74 & 0,13 & 0,46 & 0,30 \\
\hline & 15 & * & * & 0,53 & 0,09 & 0,75 & 0,28 & 0,53 & 0,14 & 0,77 & 0,16 & 0,62 & 0,12 & 0,58 & 0,09 & 0,70 & 0,23 & 0,71 & 0,28 & 0,74 & 0,25 & 0,92 & 0,56 & 0,86 & 0,12 & 0,72 & 0,12 & 0,52 & 0,30 \\
\hline & 1 & 0,11 & 0,02 & 0,08 & 0,04 & 0,08 & 0,02 & 0,16 & 0,14 & 0,46 & 0,29 & 0,37 & 0,22 & 0,69 & 0,15 & 0,69 & 0,15 & 0,86 & 0,05 & 0,90 & 0,18 & 0,84 & 0,11 & 0,63 & 0,21 & 0,84 & 0,16 & 0,47 & 0,35 \\
\hline & 2 & 0,09 & 0,01 & 0,07 & 0,02 & 0,08 & 0,02 & 0,38 & 0,35 & 0,40 & 0,28 & 0,34 & 0,26 & 0,74 & 0,20 & 0,74 & 0,20 & 0,96 & 0,33 & 0,82 & 0,20 & 0,86 & 0,10 & 0,64 & 0,23 & 0,78 & 0,17 & 0,50 & 0,32 \\
\hline Clementina & 3 & 0,09 & 0,01 & 0,07 & 0,03 & 0,21 & 0,25 & 0,37 & 0,46 & 0,72 & 0,72 & 0,10 & 0,03 & 0,33 & 0,33 & 0,33 & 0,33 & 0,82 & 0,10 & 0,86 & 0,19 & 0,88 & 0,10 & 0,67 & 0,27 & 0,81 & 0,19 & 0,46 & 0,32 \\
\hline Clementina & 4 & 0,09 & 0,01 & 0,07 & 0,02 & 0,15 & 0,21 & 0,36 & 0,47 & 0,93 & 0,63 & 0,40 & 0,29 & 0,74 & 0,15 & 0,74 & 0,15 & 0,82 & 0,13 & 0,88 & 0,19 & 0,86 & 0,13 & 0,68 & 0,17 & 0,86 & 0,21 & 0,49 & 0,34 \\
\hline & 5 & 0,11 & 0,01 & 0,07 & 0,03 & 0,12 & 0,10 & 0,35 & 0,28 & 0,61 & 0,41 & 0,43 & 0,28 & 0,36 & 0,16 & 0,36 & 0,16 & 0,83 & 0,12 & 0,87 & 0,15 & 0,84 & & 0,74 & & 0,86 & 0,22 & 0,46 & 0,33 \\
\hline & 6 & & * & 0,04 & 0,01 & 0,09 & 0,05 & 0,34 & 0,41 & 0,37 & 0,20 & 0,33 & 0,23 & 0,72 & 0,15 & 0,72 & 0,15 & 0,86 & 0,09 & 0,90 & 0,18 & 0,89 & 0,11 & 0,73 & 0,17 & 0,88 & 0,22 & 0,49 & 0,36 \\
\hline & 7 & * & * & 0,05 & 0,02 & 0,06 & 0,02 & 0,23 & 0,28 & 0,35 & 0,33 & 0,14 & $\begin{array}{l}0,09 \\
\end{array}$ & 0,63 & 0,29 & 0,63 & 0,29 & 0,86 & 0,08 & 0,87 & 0,10 & 0,88 & 0,12 & 0,77 & 0,19 & 0,81 & 0,15 & 0,48 & 0,35 \\
\hline & 8 & * & * & 0,03 & 0,00 & 0,06 & 0,02 & 0,42 & 0,46 & 0,36 & 0,22 & 0,31 & 0,21 & 0,67 & 0,20 & 0,67 & 0,20 & 0,93 & 0,19 & 0,82 & 0,15 & 0,85 & 0,12 & 0,82 & 0,17 & 0,95 & 0,34 & 0,52 & 0,35 \\
\hline & 9 & * & * & 0,01 & 0,01 & 0,06 & 0,02 & 0,39 & 0,40 & 0,57 & 0,35 & 0,39 & 0,25 & 0,73 & 0,16 & 0,73 & 0,16 & 1,00 & 0,29 & 0,85 & 0,10 & 0,86 & 0,13 & 0,70 & 0,09 & 0,83 & 0,20 & 0,49 & 0,36 \\
\hline & 10 & * & * & 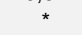 & . & 0,08 & 0,00 & 0,24 & 0,27 & 0,27 & 0,26 & 0,34 & 0,25 & 0,84 & 0,18 & 0,84 & 0,18 & 0,91 & 0,12 & 0,85 & 0,12 & 0,81 & 0,11 & 0,79 & & 0,88 & 0,17 & 0,49 & 0,37 \\
\hline & 11 & * & * & * & * & 0,08 & 0,00 & 0,32 & 0,32 & 0,64 & 0,39 & 0,47 & 0,22 & 0,76 & 0,12 & 0,76 & 0,12 & 0,89 & 0,04 & 0,88 & 0,10 & 0,84 & 0,10 & 0,70 & 0,07 & 0,84 & 0,16 & 0,46 & 0,38 \\
\hline & 12 & * & * & * & * & 0,08 & 0,00 & 0,38 & 0,40 & 0,29 & 0,29 & 0,37 & 0,28 & 0,84 & 0,22 & 0,84 & 0,22 & 0,86 & 0,09 & 0,88 & 0,11 & 0,82 & 0,17 & 0,68 & 0,07 & 0,88 & 0,19 & 0,48 & 0,36 \\
\hline & 13 & * & * & * & * & 0,07 & 0,00 & 0,34 & 0,35 & 0,62 & 0,33 & 0,43 & 0,22 & 0,74 & 0,12 & 0,74 & 0,12 & 0,91 & 0,21 & 0,86 & 0,13 & 0,83 & 0,17 & 0,74 & 0,19 & 0,84 & 0,17 & 0,49 & 0,35 \\
\hline & 14 & * & * & * & * & 0,06 & 0,00 & 0,40 & 0,42 & 0,66 & 0,37 & 0,50 & 0,23 & 0,73 & 0,18 & 0,73 & 0,18 & 0,90 & 0,03 & 0,85 & 0,22 & 0,84 & 0,10 & 0,74 & 0,10 & 0,72 & 0,15 & 0,46 & 0,35 \\
\hline & 15 & & & & & 0,08 & 0,00 & 0,12 & 0,10 & 0,21 & 0,13 & 0,27 & 0,18 & 0,70 & 0,17 & & 0,17 & 0,8 & 0,14 & 0,89 & 0,14 & 0,84 & & 0,77 & 0,07 & 0,73 & 0,17 & 0,47 & 0,35 \\
\hline & 16 & * & * & * & * & 0,07 & 0,01 & 0,15 & 0,20 & 0,26 & 0,24 & 0,29 & 0,26 & 0,76 & 0,23 & & 0,23 & 0,89 & 0,05 & 0,91 & 0,13 & & & 0,84 & 0,17 & 0,73 & 0,17 & 0,49 & 0,37 \\
\hline & 17 & * & * & * & * & 0,08 & 0,00 & 0,30 & 0,33 & 0,40 & 0,22 & 0,31 & 0,21 & 0,69 & 0,18 & 0,69 & 0,18 & 0,88 & 0,07 & 0,90 & 0,10 & 0,86 & 0,09 & 0,73 & 0,15 & 0,76 & 0,10 & 0,46 & 0,37 \\
\hline & 18 & * & * & * & * & 0,07 & 0,00 & 0,13 & 0,13 & 0,55 & 0,34 & 0,28 & 0,31 & 0,64 & 0,22 & 0,64 & 0,22 & 0,90 & 0,14 & 0,83 & 0,19 & 0,86 & 0,10 & 0,70 & 0,16 & 0,76 & 0,15 & 0,47 & 0,33 \\
\hline & * & * & * & * & * & 0,08 & 0,00 & 0,09 & 0,01 & 0,57 & 0,36 & 0,31 & 0,29 & 0,55 & 0,20 & 0,55 & 0,20 & & t & 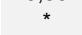 & * & * & 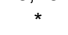 & * & * & * & * & * & se \\
\hline & * & * & * & * & * & 0,06 & 0,00 & 0,21 & 0,29 & 0,34 & & 0,15 & 0,13 & 0,67 & 0,29 & & & * & * & * & * & * & * & * & * & * & * & * & * \\
\hline & * & * & * & * & * & 0,07 & 0,01 & 0,22 & 0,29 & 0,3 & & & 0,2 & 0, & & & 0, & * & * & * & * & * & * & * & * & * & * & * & * \\
\hline Coroados & 1 & 0,75 & 0,02 & 0,71 & 0,06 & 0,70 & 0,09 & 0,68 & 0,08 & 0,73 & 0,08 & 0,62 & 0,05 & 0,59 & 0,04 & 0,59 & 0,04 & 0,65 & 0,05 & 0,83 & 0,14 & 0,82 & 0,24 & 0,71 & 0,03 & 0,73 & 0,11 & 0,41 & 0,34 \\
\hline & 2 & 0,76 & 0,01 & 0,71 & 0,06 & 0,69 & 0,10 & 0,67 & 0,07 & 0,72 & 0,06 & 0,62 & 0,05 & 0,59 & 0,03 & 0,59 & 0,03 & 0,63 & 0,04 & 0,85 & 0,13 & 0,88 & 0,19 & 0,74 & 0,02 & 0,77 & 0,09 & 0,41 & 0,36 \\
\hline & 3 & 0,76 & 0,01 & 0,71 & 0,05 & 0,71 & 0,10 & 0,68 & 0,07 & 0,73 & 0,06 & 0,62 & 0,05 & 0,60 & 0,05 & 0,60 & 0,05 & 0,64 & 0,06 & 0,82 & 0,14 & 0,86 & 0,12 & 0,73 & 0,03 & 0,80 & 0,12 & 0,41 & 0,35 \\
\hline Monteirc & 1 & 0,75 & 0,02 & 0,68 & 0,08 & 0,68 & 0,06 & 0,68 & 0,04 & 0,7 & 0,06 & 0,70 & 0,03 & 0,69 & 0,26 & 0,69 & 0,26 & 0,71 & 0,08 & 0,86 & 0,10 & 0,64 & 0,1 & 1,05 & 0,10 & 0,84 & 0,25 & 0,48 & 0,35 \\
\hline (cine & 2 & 0,7 & 0,0 & 0,66 & 0,07 & 0,70 & 0, & 0 & & & & & 0, & 0, & 0 , & & & & & & & & & 0,81 & & & & 0,45 & 0,31 \\
\hline & 3 & 0,76 & 0,00 & 0,67 & 0,06 & 0,69 & 0,05 & 0,72 & 0,05 & 0,72 & 0,11 & 0,71 & 0,07 & 0,65 & 0,21 & 0,65 & 0,21 & 0,72 & 0,15 & 0,83 & 0,11 & 0,64 & 0,18 & 1,03 & 0,12 & 0,83 & 0,24 & 0,48 & 0,34 \\
\hline & 1 & 0,42 & 0,08 & 0,27 & 0,04 & 0,29 & 0,07 & 0,27 & 0,05 & 0,29 & 0,04 & 0,24 & 0,08 & 0,67 & 0,16 & 0,67 & 0,16 & 0,97 & 0,38 & 0,67 & 0,24 & 0,76 & 0,14 & 0,67 & 0,09 & 0,72 & 0,10 & 0,46 & 0,31 \\
\hline Glicério & 2 & 0,34 & 0,00 & 0,26 & 0,04 & 0,29 & 0,05 & 0,31 & 0,13 & 0,27 & 0,07 & 0,27 & 0,07 & 0,64 & 0,17 & 0,64 & 0, & 0,97 & 0,40 & 0,66 & 0,23 & 0,82 & 0,07 & 0,66 & 0,11 & 0,76 & 0,16 & 0,47 & 0,32 \\
\hline & 3 & 0,33 & 0,00 & 0,27 & 0,07 & 0,31 & 0,03 & 0,29 & 0,08 & 0,30 & & 0,29 & 0,05 & 0,64 & 0,16 & & 0 , & 1,0 & 0,40 & 0,68 & 0,24 & 0,81 & & 0,67 & 0,13 & 0,60 & 0,14 & 0,47 & 0,31 \\
\hline & 4 & 0,34 & 0,00 & 0,27 & 0,14 & 0,3 & 0 & & & 0 & & & 0 & 0 & & & & 1, & 0 & 0 , & & & & & & & 0,01 & 0,48 & 0,38 \\
\hline & 5 & 0,60 & 0,01 & 0,53 & 0,17 & 0,63 & 0,11 & 0,54 & 0,18 & 0,64 & 0,0 & 0,77 & 0,2 & 0,80 & 0,16 & 0,80 & 0,16 & 0,82 & 0,02 & 0,84 & 0,18 & 0,83 & 0,1 & 0,68 & 0,07 & 0,63 & 0,08 & 0,43 & 0,36 \\
\hline & 6 & & & 0,68 & 0,05 & 0,68 & 0,06 & 0,59 & 0,2 & 0,4 & & 0, & 0,23 & 0,79 & 0,02 & 79 & 0, & 0,7 & 0 , & 0,80 & 0,25 & 91 & & 0,69 & 12 & 0,60 & 0,07 & 44 & 0,34 \\
\hline & 7 & * & * & 0,48 & 0,32 & 0,62 & 0,12 & 0,65 & 0,1 & 0 & & 0,66 & 0,1 & 0,7 & 0,02 & 79 & 0, & 0,6 & & 0,84 & 0 , & & 0,10 & 0,61 & 0,15 & 0,71 & 0,04 & 0,42 & 0,34 \\
\hline & 8 & * & * & 0,16 & 0,11 & 0,28 & 0,05 & 0,32 & 0,10 & 0,27 & 0,05 & 0,29 & 0,09 & 0,65 & 0,18 & 0,65 & 0, & 1,05 & 0,3 & 0,70 & 0,25 & 0,82 & 0,1 & 0,58 & 0,11 & 0,68 & 0,09 & 0,47 & 0,32 \\
\hline & 9 & * & * & 0,18 & 0,08 & 0,35 & 0,09 & 0,27 & 0,05 & 0,3 & & 0 & 0,1 & 0,63 & & & & 1,2 & 0 & & 0,19 & & & & & 0,64 & 0,09 & 0,48 & 0,36 \\
\hline & 1 & 0,56 & 0,14 & 0,47 & 0,19 & 0,55 & 0,47 & 0,52 & 0,3 & 0,53 & 0,2 & 0, & 0,10 & 0,77 & 0, & 0,7 & 0, & 0,9 & 0,0 & 0, & 0 , & & 0 & 0,7 & 08 & 0,80 & 0,17 & 0,47 & 0,37 \\
\hline Guaraçai & 2 & & 0,04 & 0,52 & 0,17 & 0,38 & 0,25 & & 0,3 & 0,54 & & & 0,0 & 0,77 & & & & & 0, & 0, & 0, & & & 66 & 08 & 0,76 & 0,13 & 0,46 & 0,37 \\
\hline & 3 & & 0,1 & 0 , & 0,33 & 0,51 & 0,4 & & $0, C$ & 0 & & 0, & 0,0 & 0 & 0 & 0,70 & & 0,9 & 0 & & 0,12 & & 0,1 & 0,7 & 0,12 & 0,81 & 0,11 & 0,46 & 0,35 \\
\hline & 4 & 0,56 & 0,01 & 0,52 & 0,15 & 0,38 & 0,22 & 0,38 & 0,15 & 0,50 & 0,09 & 0,65 & 0,10 & 0,75 & 0,14 & 0,75 & 0,1 & 0,91 & 0,1 & 0,78 & 0,11 & 0,82 & 0,1 & 0,69 & 0,12 & 0,83 & 0,14 & 0,47 & 0,35 \\
\hline & 5 & 0,55 & 0,17 & 0,42 & 0,14 & 0,23 & $\begin{array}{l}0,06 \\
0,05\end{array}$ & 0,49 & 0,35 & 0,53 & & 0,76 & 0,0 & 0,86 & 0,07 & & 0, & 0,71 & $\begin{array}{l}0,09 \\
0,0\end{array}$ & 0,74 & 0,20 & & 0,1 & 0,72 & 0,10 & 0,78 & 0,14 & 0,45 & 0,34 \\
\hline & 6 & 0,59 & 0,03 & 0,43 & 0,16 & 0,26 & 0, & & 0 , & 0 & & & 0, & 0 , & & & 0 , & & 0 & 0, & 0 , & & & & & & 0,12 & & 0,35 \\
\hline & 7 & 0,41 & 0,03 & 0 , & 0 & 0, & 0,4 & & 0, & 0 & & & 0, & 0, & & & & & & 0, & & & & & & 0 & & 46 & 0,34 \\
\hline & 8 & & & 0,39 & 0,00 & 0,37 & 0,2 & 0 & 0,04 & 0,42 & & 0, & 0,11 & 0,71 & 0,14 & 0,71 & 0 , & 0,8 & 0 , & 0,75 & 0,16 & 0,76 & 0,1 & 0,72 & 0,11 & 0,76 & 0,13 & 0,44 & 0,33 \\
\hline & 9 & * & * & 0,40 & 0,00 & 0,43 & 0,27 & 0,43 & 0,31 & 0,48 & 0,20 & 0,71 & 0,10 & 0,78 & 0,11 & 0,78 & 0,11 & 0,88 & 0,13 & 0,82 & 0,13 & 0,74 & 0,10 & 0,70 & 0,08 & 0,79 & 0,12 & 0,45 & 0,35 \\
\hline & 10 & * & * & 0,39 & 0,00 & 0,40 & 0,12 & $\begin{array}{l}0,76 \\
0,76\end{array}$ & 0,40 & 0,47 & & 0,73 & 0,15 & 0,80 & 0,07 & & 0,07 & $\begin{array}{l}0,91 \\
\end{array}$ & 0,04 & & 0,12 & & & 0,71 & $\begin{array}{l}0,07 \\
0,07\end{array}$ & 0,80 & 0,11 & 0,45 & 0,37 \\
\hline & 11 & $*$ & * & 0,39 & 0,00 & 0,66 & 0,5 & 0 & 0,2 & 0 & & & 0 & 0 , & & & & & & & & & & & & & & & 0,36 \\
\hline & 12 & * & * & 0 & 0, & 0 & 0 , & 0 , & 0 , & & & & 0 , & 0 & & & & 0 & & & & & & & & 0,77 & 11 & 52 & 34 \\
\hline & 1 & 0,61 & 0,01 & 0,62 & 0,06 & 0,65 & 0,11 & 0,71 & 0,13 & 0,82 & 0,11 & 0,72 & 0,18 & 0,70 & 0,09 & 0,70 & 0,09 & 0,77 & 0,08 & 0,88 & 0,13 & 0,90 & 0,10 & 0,74 & 0,05 & 0,87 & 0,17 & 0,46 & 0,37 \\
\hline & 2 & 0,61 & 0,01 & 0,62 & 0,05 & 0,64 & 0,12 & 0,71 & 0,16 & 0,77 & 0,09 & 0,75 & 0,18 & 0,68 & 0,09 & 0,68 & 0,09 & 0,83 & 0,17 & 0,84 & 0,20 & 0,87 & 0,11 & 0,75 & 0,03 & 0,77 & 0,13 & 0,45 & 0,35 \\
\hline & 3 & 0,59 & 0,01 & 0,60 & 0,06 & 0,65 & 0,14 & 0,74 & 0,14 & 0,79 & 0,10 & 0,73 & 0,18 & 0,68 & 0,09 & 0,68 & 0,09 & 0,77 & 0,07 & 0,85 & 0,14 & 0,85 & 0,13 & 0,75 & 0,02 & 0,80 & 0,12 & 0,44 & 0,36 \\
\hline
\end{tabular}


Tabela 5. Médias e desvios-padrões anuais de cada ponto de coleta de água dos municípios de Guzolândia, Ilha Solteira, Itapura, Lavínia. Lourdes, Luiziânia, Mirandópolis, Murutinga do Sul, Nova Castilho, Nova Independência, Nova Luzitânia, Penápolis, Pereira Barreto, Piacatu, Rubiácea, Santo Antônio do Aracanguá, Sud Menucci, Suzanópolis, Turiúba e Valparaíso, de 2004 a 2017

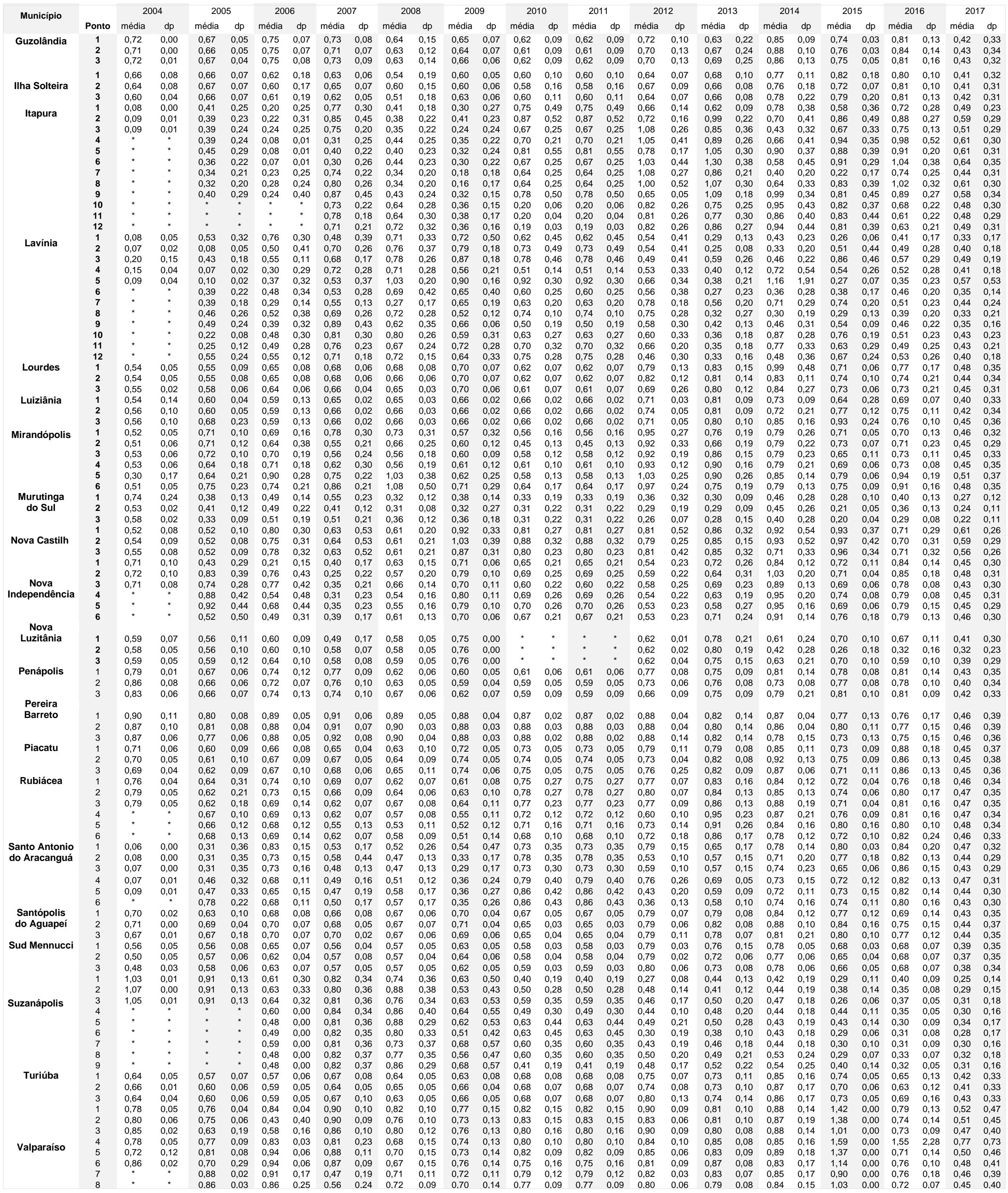




\section{DISCUSSÃO}

Neste estudo foi observado que $52,47 \%$ das amostras analisadas atingiram os valores do intervalo considerado ótimo $(0,55$ a $0,84 \mathrm{mgF} / \mathrm{L})$, de acordo com as recomendações do CECOL $(0,55$ a $0,84 \mathrm{mgF} / \mathrm{L})$, fundamentando-se no critério de máximo benefício de prevenção de cárie e risco mínimo no desenvolvimento de fluorose; quase um quinto delas $(19,38 \%)$ estava dentro do intervalo entre 0,85 e 1,14 $\mathrm{mgF} / \mathrm{L}$, que apesar de não oferecer o risco mínimo do método, proporciona o máximo benefício preventivo. Ou seja, pode-se dizer que $71,85 \%$ das amostras analisadas garantem a máxima eficácia da fluoretação na prevenção de cárie dentária.

As Tabelas 2 a 5 mostram a evolução de cada ponto de coleta dos 40 municípios englobados no projeto por meio de suas médias anuais, de 2004 a 2017. Torna-se importante para os gestores de saúde e responsáveis locais pelo tratamento de água a divulgação de tais resultados, para que seja possível avaliar o desenvolvimento do método em suas respectivas cidades, principalmente naquelas que possuem mais de uma fonte de captção de água, pois foi verificado que onde havia mais que 3 pontos de coleta (correspondente a 1 fonte de captação), a variação dos resultados entre os pontos tendia a ser maior, justamente por conta da diferença entre as procedências da água.

Desta forma, ressalta-se que a metodologia adotada pelo projeto de heterocontrole da FOA-Unesp, que estabelece os pontos de coleta das amostra de acordo com a localização e o número das fontes de abastecimento de água presentes nos municípios, proporciona aos pesquisadores e gestores o entendimento da situação de cada localidade, pois as médias anuais da cidade podem não representar a real condição a qual está exposta toda sua população, sobretudo nas localidades com diferentes fontes de captação de água.

Birigui, uma das cidades inseridas no projeto, possui complexa rede de distribuição, composta por Estação de Tratamento de Água (ETA), poços semiartesianos, artesianos e profundos, junções de tubulação de poços profundos com a ETA e fontes alternativas, totalizando 42 pontos de coleta. A FOA-Unesp realizou estudos nesse município, tendo sido evidenciado que aproximadamente $51 \%$ de suas amostras de água continham níveis acima de $0,84 \mathrm{mgF} / \mathrm{L}^{12,13}$, sendo seus poços profundos os responsáveis por esta situação. Uma das estratégias propostas para resolução desse entrave foi a mistura de águas dos poços profundos com outras fontes de captação, na tentativa de diluir os níveis elevados do íon. Os pontos 4,5 e 6 , e 10,11 e 12 de Birigui são os relativos aos poços profundos, e os pontos 7,8 e 9, e 13,14 e 15 são os provenientes das junções de tubulações dos poços profundos com as água oriundas da Estação de Tratamento de Água do município, podendo ser observado na Tabela 3 suas características com relação aos teores de fluoreto.

Desde o início do projeto, reuniões anuais com os responsáveis pelo abastecimento de água, secretários de saúde e coordenadores de saúde bucal de cada cidade foram realizadas para atualização das informações sobre suas redes de abastecimento de água e operacionalização do método de fluoretação, bem como para se enfatizar a importância e estimular as parcerias entre a universidade e os municípios. Em tais ocasiões foram verificadas, analisadas e discutidas com as autoridades locais os principais obstáculos que dificultam ou impedem o alcance de teores recomendados de fluoreto, além de se enfatizar a relevância do hetecontrole na prevenção de cárie e fluorose dentária.

$\mathrm{O}$ estabelecimento de parcerias entre a universidade, prefeituras e serviços de saúde, se mostaram muito úteis, sendo importantes estratégias que geram benefícios para todas as partes envolvidas, incluindo a própria comunidade. Os resultados enviados mensalmente aos responsáveis pelo tratamento de água, secretários de saúde e coordenadores de saúde bucal, auxiliaram os gestores das localidades a melhor direcionar suas estratégias e ações, objetivando adequações ou mudanças na operacionalização da medida de acordo com os planejamentos de cada município.

Apenas um município apresentou teores de flúor de todos os seus pontos abaixo do recomendado. Murutinga do Sul, durante os 13 anos do estudo, não alcançou os níveis de fluoreto mínimos necessários para que o método proporcione seu efeito preventivo. Um estudo evidenciou que as principais dificuldades verificadas na operacionalização do método estão relacionadas à manutenção dos equipamentos, aos recursos financeiros designados à sua execução, treinamento de recursos humanos ou complexidade da rede de distribuição de água ${ }^{14}$.

A eficácia da fluoretação já foi há muito comprovada, e revisões sistemáticas confirmam este fato: a pesquisa de McDonalgh et al. ${ }^{15}$ evidenciou que em regiões fluoretadas havia um número maior de crianças sem cárie em comparação com áreas não fluoretadas; a revisão sistemática de IheozorEjiofor, que objetivou foi analisar os efeitos da fluoretação na prevenção da cárie e também nos riscos de se desenvolver de fluorose dentária, comprovou que a medida é eficaz na redução dos níveis de cárie na dentição decídua e permanente em crianças ${ }^{16}$.

Para a saúde pública, o baixo custo é outra grande vantagem do método: na cidade de São Paulo, o custo médio per capita/ano foi de R $\$ 0,08$ (US\$ 0,03), em 2003, sendo que o valor acumulado de 1985 a 2003 foi de R\$ 1,44 por habitante ${ }^{17}$, sendo, portanto, um valor muito aquém quando comparado a procedimentos odontológicos, tais como restaurações, obturações, extrações e próteses.

Com os achados do estudo, constata-se que o heterocontrole é uma relevante estratégia na saúde pública que auxilia os serviços públicos de saúde a adequarem os níveis de flúor nas águas de abastecimento, de forma que o direito da população a receber o produto de qualidade e que garanta o benefício da prevenção de cáries seja garantido, considerando ainda que a adição de fluoreto nas águas é Lei Federal.

\section{CONCLUSÃO}

A maior parte dos municípios possui fluoreto nos teores preconizados em suas águas de abastecimento público. No decorrer do projeto, houve grande melhora na adequação do método nas localidades. A vigilância e o heterocontrole são importantes estratégias que auxiliam o método a alcançar seu efeito preventivo, garantindo o direito da população a receber água de qualidade para seu consumo.

\section{REFERÊNCIAS}

1. Moimaz SAS, Saliba NA, Saliba O, Sumida DH, Souza NP, Chiba FY et al. Water fluoridation in 40 Brazilian cities: 7 year analysis. J Appl Oral Sci. 2013; 21(1):13-9.

2. Viegas AR. Fluoretação da água de abastecimento público. Rev Bras Med. 1989; 46:209-16.

3. Murray JJ. Uso correto de fluoretos na saúde pública. São Paulo: Santos; 1992.

4. Centers for Disease Control and Prevention. Achievements in Public Health, 1900-1999: fluoridation of drinking water to prevent dental caries. MMWR 1999; 48:933-40.

5. Pinto VG. Prevenção da cárie dental. In: Pinto VG. Saúde bucal: odontologia social e preventiva. 3rd ed. São Paulo: Santos; 1992. p. 275-328.

6. Saliba NA, Moimaz SAS, Casotti CA, Pagliari AV. Dental caries of lifetime residents in Baixo Guandu, Brazil, fluoridated since 1953. J Public Health Dent. 2008; 68(2):119-21.

7. Brasil. Lei $n^{\circ} 6.050$, de 24 de maio de 1974. Dispõe sobre a obrigatoriedade da fluoretação das águas em sistema de 
abastecimento. Diário Oficial da República Federativa do Brasil 1974; 27 maio.

8. Ministério da Saúde. Diretrizes da Política Nacional de Saúde Bucal http://bvsms.saude.gov.br/bvs/publicacoes/ politica_nacional_brasil_sorridente.pdf (acessado 6/ Abr/ 2015).

9. Narvai PC. Cárie dentária e flúor: uma relação do século XX. Ciênc Saúde Coletiva. 2000; 5(2):381-92.

10. Cury JA, Lima YBO, Vieira Filho W. Análise de flúor com eletrodo específico. UNICAMP: Campinas; 2001.

11. Universidade de São Paulo. Consenso técnico sobre classificação de águas de abastecimento público segundo o teor de flúor. São Paulo: Faculdade de Saúde Pública da Universidade de São Paulo; 2011.

12. Moimaz SAS, Santos LFP. Estudo longitudinal da fluoretação das águas em município com complexa rede de distribuição: dez anos de estudo. Arch Health Invest. 2015; 4(5):11-6.

13. Santos LFP, Chiba FY, Moimaz SAS, Saliba O. Estudo da concentração de flúor nas águas de abastecimento público relacionada às variações pluviais. Rev Ciênc Plural. 2016; 2(2):3-13.

14. Moimaz SAS, Garbin CAS, Iglesias GF, Chiba FY, Sumida DH, Saliba O. Dificuldades enfrentadas no processo de fluoretação das águas de abastecimento público. Rev Bras Pesq Saúde. 2015; 17(1):87-94.

15. McDonalgh MS, Whiting PF, Wilson PM, Sutton AJ, Chestnutt I, Cooper J, et al. Systematic review of water fluoridation. BMJ. 2000; 321:855-9.

16. Iheozor-Ejiofor Z, Worthington HV, Walsh T, O'Malley L, Clarkson JE, Macey R et al. Water fluoridation for the prevention of dental caries. Cochrane Database Syst Rev 2015; 6:CD010856.

17. Frias AC, Narvai PC, Araújo ME, Zilbovicius C, Antunes JLF. Custo da fluoretação das águas de abastecimento público, estudo de caso: município de São Paulo, Brasil, período de 1985-2003. Cad Saúde Pública. 2006; 22(6):1237-46

\section{CONFLITO DE INTERESSES}

Os autores declaram não haver conflitos de interesse.

\section{AUTOR PARA CORRESPONDÊNCIA}

Suzely Adas Saliba Moimaz

sasaliba@foa.unesp.br

Submetido em 20/04/2018

Aceito em 30/05/2018 